\title{
Study on phase transformation of CMnSi steel when heat treatment
}

\author{
Nguyen Duong Nam ${ }^{1,}{ }^{*}$, Hoang Thanh Thuy ${ }^{1}$, Dinh Van Hien ${ }^{2}$ and Sai Manh Thang ${ }^{2}$ \\ ${ }^{1}$ Vietnam Maritime University, 484 Lach Tray, Le Chan, Hai Phong Vietnam. \\ 2 Military Institute of Science and Technology Ha Noi, Vietnam.
}

GSC Advanced Engineering and Technology, 2021, 01(01), 001-005

Publication history: Received on 01 December 2020; revised on 12 December 2020; accepted on 14 December 2020

Article DOI: https://doi.org/10.30574/gscaet.2021.1.1.0021

\begin{abstract}
After manufacturing, if the CMnSi steel was heat treatment, it would create the multi-phase microstructure consists of highly ductility ferrite matrix, martensite, bainite and amounts of austenite. Thereby, the strength and ductility of the steel were improved. In the process of improving the quality of steel, there will be two processes: the plastic deformation process and the heat treatment process. In this paper, we present the study on the microstructure and mechanical properties of $\mathrm{CMnSi}$ steel which was heated. The heat treatment process of CMnSi steel is a special heat treatment process including the process of heating the steel to austenite temperature at $900{ }^{\circ} \mathrm{C}$ then keeping the heat to ensure uniformity of steel. This steel was cooled quickly from austenite temperature to phase transformation temperature which had bainite transformation equal to about $400{ }^{\circ} \mathrm{C}$ (this temperature is determined by CCT diagram). The results of microstructure analysis show that by the heat treatment process, the microstructure of steel is included three main phases: ferrite, bainite, and residual austenite. The results of mechanical tests show that after the heat treatment, the strength limit of steel is $1141 \mathrm{MPa}$, the elastic limit is $943 \mathrm{MPa}$ and the elongation is $36 \%$.
\end{abstract}

Keywords: Transformation phase; Multi-phase; Bainite; ferrite; Austenite; heat treatment

\section{Introduction}

Another type of the third-generation of AHSS is TRIP aided bainite ferrite (TBF) steel. This steel uses retained austenite with the TRIP effect along with a bainitic microstructure to increase the strength and formability. Bainite is traditionally defined as a mixture of non-lamellar arrays of carbides in ferrite formed by both shear and diffusional transformation. TBF steels generally contain carbide free bainite, making it a lath structured ferritic phase. TBF steel is produced using an austempered processing technique roughly analogous to one-step Q\&P. The major difference in the processing is that for TBF the hold temperature is above MS. TBF processing (see Fig. 1) includes an austenitization, followed by a controlled quench and isothermal hold to form bainite [1-8].

\footnotetext{
${ }^{*}$ Corresponding author: Nguyen Duong Nam

Vietnam Maritime University, 484 Lach Tray, Le Chan, Hai Phong Vietnam.
} 


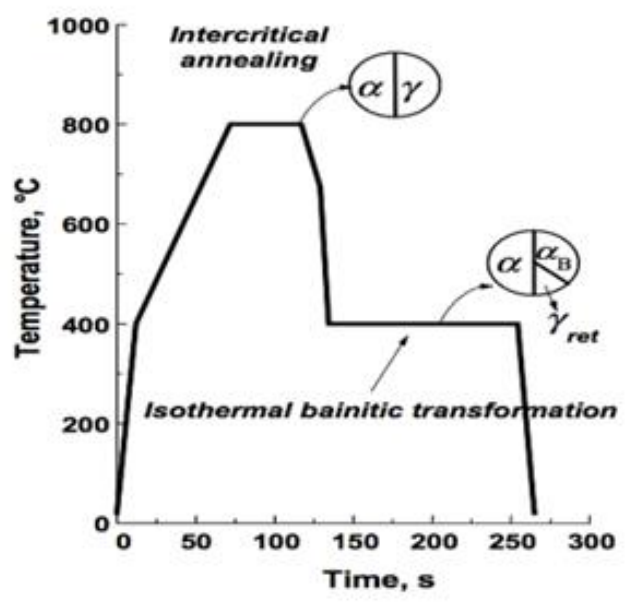

Figure 1 Heat treatment process of TBF steel

The microstructure characteristics of TBF steel (see Fig. 2) are fine regular carbide-free bainite ferrite strip, thin-film retained austenite and massive retained austenite distributed on the bainite-ferrite matrix and very few tempered martensites. High toughness of TBF steel is mainly due to its fine regular lath structure, the TRIP effect of rich carbon retained austenite and the long-range internal stress of untransformed thin-film retained austenite [7 - 11].
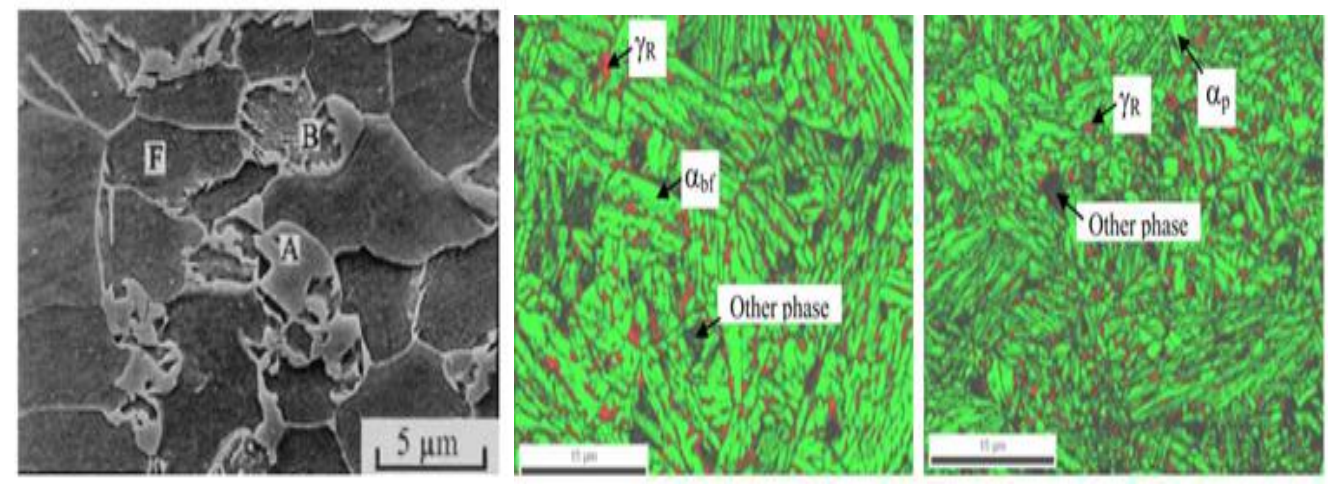

Figure 2 Microstructure of TBF steel

In this chapter, we present the study on the microstructure and mechanical properties of CMnSi steel, which was heated.

\section{Material and methods}

The chemical composition of samples is shown in Table 1.

Table 1 Optimized volume fraction in eight layers for surface temperatures.

\begin{tabular}{|l|l|l|l|l|l|l|}
\hline Sample & Fe & C & Si & Mn & P & S \\
\hline No.1 & Bal & $0.2-0.25$ & $1.3-1.8$ & $1.4-1.6$ & 0.08 & 0.02 \\
\hline
\end{tabular}

A $30 \mathrm{~kg}$ cast ingot prepared in an induction furnace was cut into small blocks, followed by forging and hot rolling at $50 \%$ total thickness reduction. After hot rolling, 70 (width) $\mathrm{mm} \times 10$ (thickness) $\mathrm{mm} \times$ freely length samples were cold rolled to $2 \mathrm{~mm}$ with $60 \%$ thickness reduction and heat-treated via two stages: (i) annealing at the temperature $900{ }^{\circ} \mathrm{C}$ and holding times 15 minutes because at the annealing range, the volume fraction of ferrite in about from 50 to $60 \%$ determined by experiment; (ii) after annealing, the steel samples were fast-cooled to temperatures of $420^{\circ} \mathrm{C}$ with three isothermal holding times of 1,2 and 10 minutes. The steel samples were heat treated in salt baths. 


\section{Results}

After casting, the microstructure appears branched structure (see Fig. 3). This type of structure greatly affects the mechanical properties of steel.

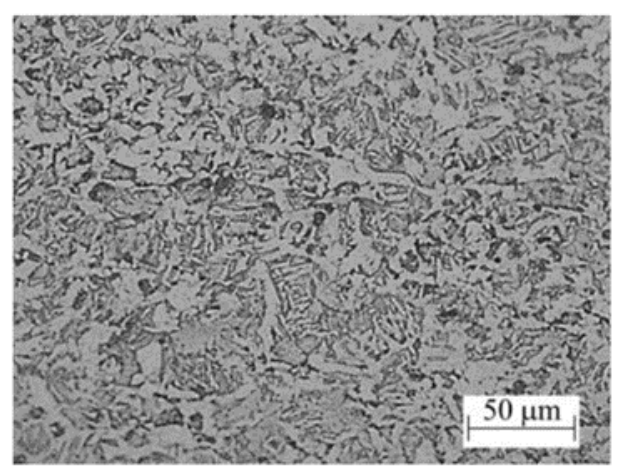

Figure 3 Microstructure of sample after casting

After forging, the branched structure in the casting process was no longer present (see Fig. 4). The microstructure became uniform. This type of structure will facilitate the next heat-treatment process. However, the microstructure of the sample has a larger grain size, which affects mechanical properties.
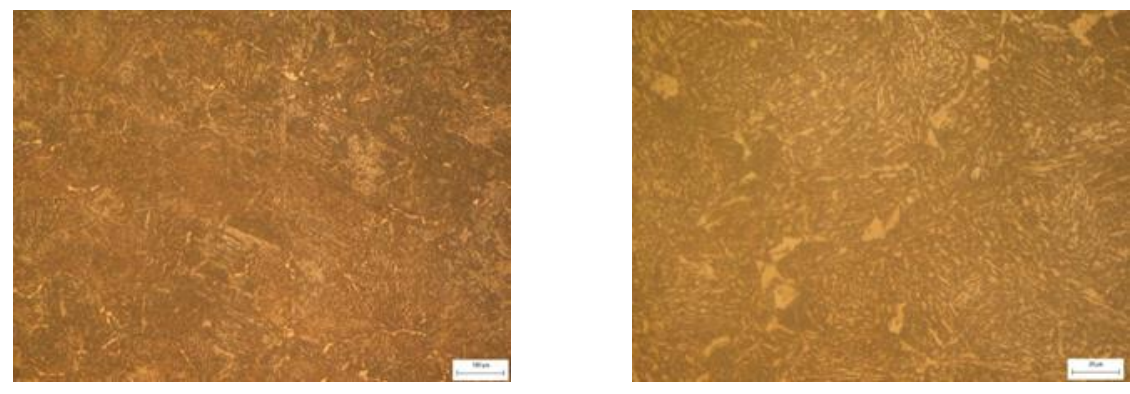

Figure 4 Microstructure of sample after forging

By OM, the grain size was $20-30 \mu \mathrm{m}$. In the cold deformation process, the microstructure receives fine particles which will greatly affect the structure and mechanical properties of steel after heat treatment (see Fig. 5). In addition to the fine grain, after cold deformation, in the structure, the phases are also more evenly dispersed.
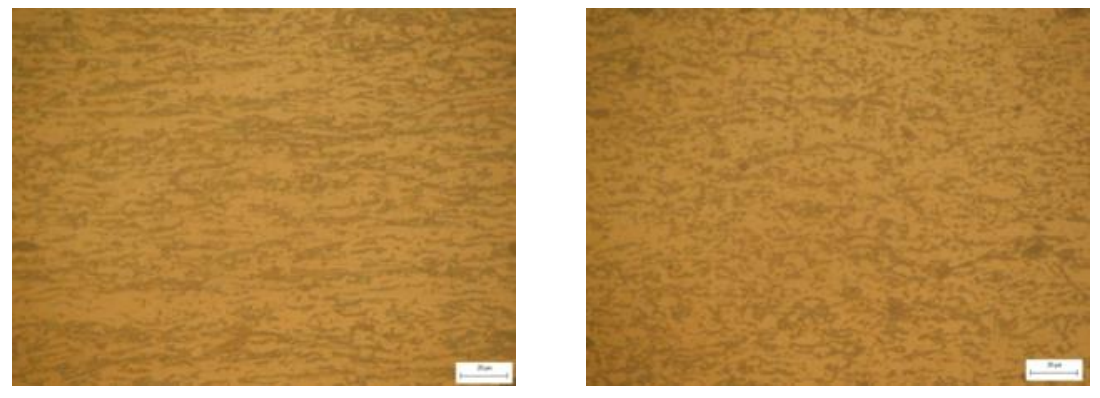

Figure 5 Microstructure of sample after cold deformation

Then, the microstructure of the sample after heat treatment at $420^{\circ} \mathrm{C}$ during different times $(1,2$ and 10 minutes $)$ was studied, see Fig. 6 a, b, c, respectively. 

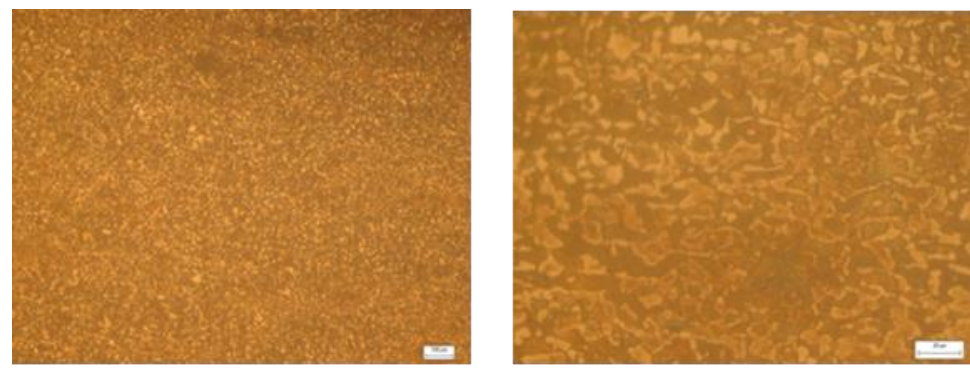

(a)
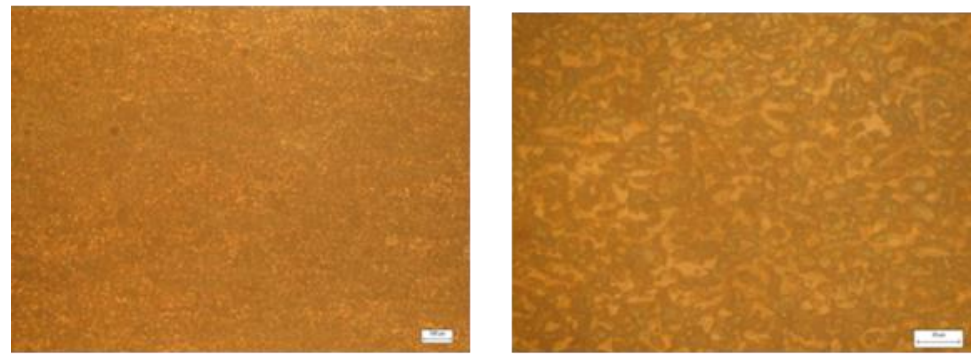

(b)
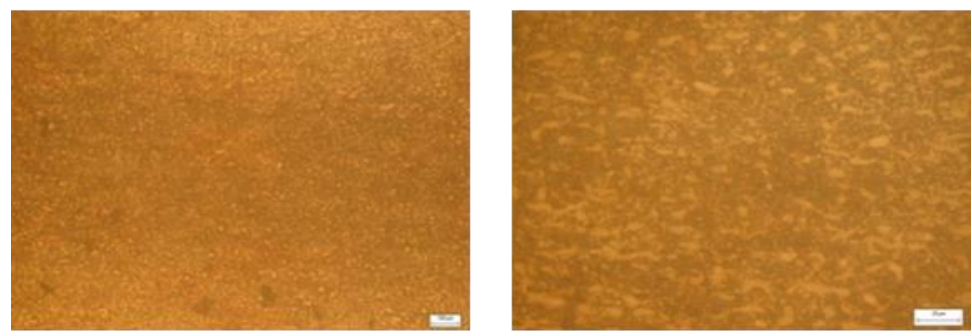

(C)

Figure 6 Microstructure of sample after heat treatment at $420{ }^{\circ} \mathrm{C}$ for different times $(1,2$ and 10 minutes $)$

After cold deformation and heat treatment, the microstructure was changed. The microstructure has many phases. With this heat treatment process, by increasing to $900^{\circ} \mathrm{C}$ and annealing for 15 minutes and fast cooling to about $420{ }^{\circ} \mathrm{C}$ with heating in 1, 2 and 10 minutes, the structure has bainite, austenite, and ferrite. The ratio and size between phases will greatly affect the mechanical properties of the steel. When the sample was processed with increased holding times at $420^{\circ} \mathrm{C}$, the grain size was changed. These white phases of the sample held for 10 minutes (see Fig. 7) would smaller than the sample for 1 minute. However, by $\mathrm{OM}$, these phases are difficult to identify.
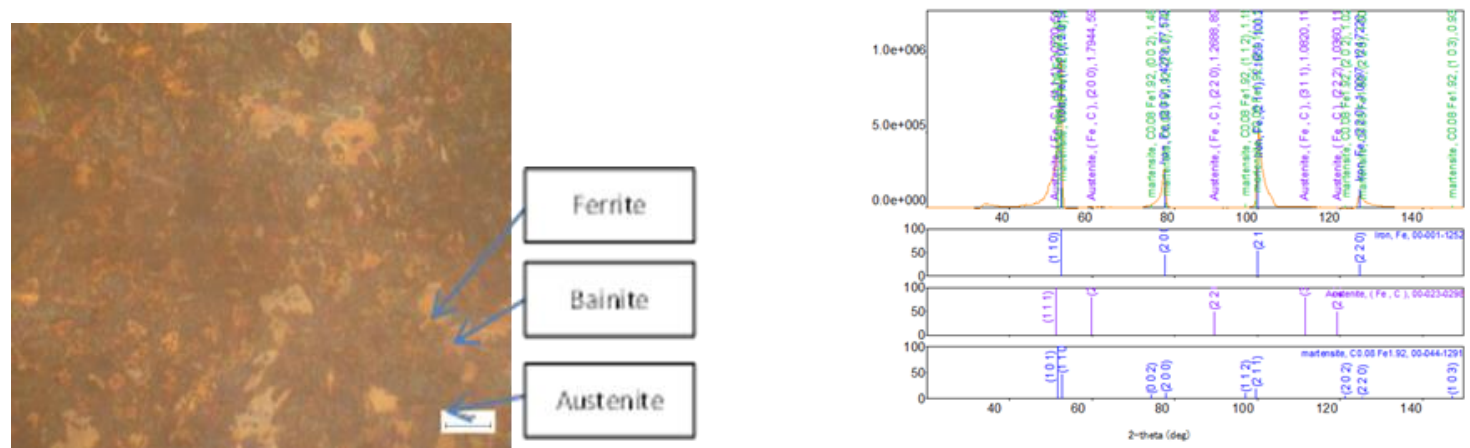

Figure 7 Microstructure and X-ray of the sample after heat treatment at $420^{\circ} \mathrm{C}$ during 10 minutes

By OM and X-ray, the microstructure has ferrite, bainite, and austenite.

The mechanical properties of the sample are present in Table 2. 
Table 2 Mechanical properties of the sample

\begin{tabular}{|l|l|l|l|}
\hline & $\begin{array}{l}\text { UTS Tensile strength } \\
\text { (N/mm) }\end{array}$ & $\begin{array}{l}\text { El Elongation } \\
\mathbf{( \% )}\end{array}$ & $\begin{array}{l}\text { UTS } \times \text { El } \\
\text { (MPa·\%) }\end{array}$ \\
\hline Sample for 1 minutes & 1247.83 & 40.2 & $50,162.7$ \\
\hline Sample for 2 minutes & 1522.69 & 38.98 & $59,354.5$ \\
\hline Sample for 10 minutes & 1514.95 & 41.88 & $63,446.1$ \\
\hline
\end{tabular}

It was found from Table 2 that all of the heat treatment parameters are influence significantly UTS $\times$ El; among them, the time has the strongest influence on UTS $\times$ El compared to that of the other two factors. It was found from samples for 1 minute, for 2 minutes and 10 minutes, the heat treatment parameters have a fairly similar influence on El but these samples change UTS. The value of UTS $\times$ El can be obtained over 63,466.1 (MPa-\%) at 10 minutes.

\section{Conclusion}

The results of microstructure analysis show that: by the heat treatment process, the microstructure of steel is included three main phases: ferrite; bainite and residual austenite. The results of the mechanical tests show that after the heat treatment, the tensile strength of steel is $1514.95 \mathrm{~N} / \mathrm{mm}$; and the elongation is $41.88 \%$ and the value of UTS $\times$ El has $63,466.1(\mathrm{MPa} * \%)$.

\section{References}

[1] Demeri MY. Evolving Advanced High-Strength Steel Grades. Advanced High-Strength Steels: Science, Technology, and Applications. 2013:263-74.

[2] Kuziak R, Kawalla R, Waengler S. Advanced high strength steels for automotive industry. Archives of civil and mechanical engineering. 2008 Jan 1;8(2):103-17.

[3] Kliber J, Plestilova G, Zacek O, Somani MC. Effects of thermomechanical processing on microstructure and mechanical properties multiphase steels exhibiting a TRIP effect. InMaterials science forum 2007 (Vol. 539 , pp. 4357-4362). Trans Tech Publications Ltd.

[4] Jacques P, Girault E, Catlin T, Geerlofs N, Kop T, Van Der Zwaag S, Delannay F. Bainite transformation of low carbon Mn-Si TRIP-assisted multiphase steels: influence of silicon content on cementite precipitation and austenite retention. Materials Science and Engineering: A. 1999 Dec 15;273:475-9.

[5] Keskes-Ammar L, Feki-Chakroun N, Rebai T, Sahnoun Z, Ghozzi H, Hammami S, Zghal K, Fki H, Damak J, Bahloul A. Sperm oxidative stress and the effect of an oral vitamin E and selenium supplement on semen quality in infertile men. Archives of andrology. 2003 Jan 1;49(2):83-94.

[6] M. De Meyer, D. Vanderschueren, K. De Blauwe, B.C.D. Cooman, 41st MWSP Conference Proceedings, ISS, 1999, pp. 483-491.

[7] Jacques PJ. Transformation-induced plasticity for high strength formable steels. Current Opinion in Solid State and Materials Science. 2004 Jun 1;8(3-4):259-65.

[8] Zhang ZC, Zhu FX, Li YM. Effect of thermomechanical control processing on microstructure and mechanical properties of Fe-0. 2C-1. 44Si-1. 32Mn hot rolled TRIP steel. Journal of Iron and Steel Research, International. 2010 Jul 1;17(7):44-50.

[9] Lee CG, Kim SJ, Oh CS, Lee S. Effects of heat treatment and Si addition on the mechanical properties of $0.1 \mathrm{wt} \% \mathrm{C}$ TRIP-aided cold-rolled steels. ISIJ international. 2002 Oct 15;42(10):1162-8.

[10] Bhadeshia H.K.D.H. Microstructure bainite in steel-transformation and properties. The University Press, Cambridge. 2001.

Koh-ichi Sugimoto, Tomohiko Hojo, Ashok Srivastava. An Overview of Fatigue Strength of Case-Hardening TRIPAided Martensitic Steels. Metals. 2018, Vol.8, No.5, p.355. 